\title{
SE O ORDINÁRIO OCUPA O PALCO (E A SALA DE AULA)
}

\section{If the Ordinary Occupies the Stage (and the classroom)}

\author{
André Magela \\ Universidade Federal de São João del Rei - UFSJ
}

Resumo: O presente artigo analisa algumas peças teatrais quanto ao modo como expõem elementos do comum e do ordinário, oriundos da vida cotidiana, sugerindo implicitamente ao espectador uma percepção mais teatral de sua vida, e fomentando a produção de outras possibilidades de viver, alternativas aos modos hegemônicos de sentir. $E$ estas peças podem ser subsídios a modos de ver a arte e a produção artística que sejam interessantes para a educação teatral em escolas.

Palavras-chave: Recepção teatral; Educação teatral; Teatro e política.

Abstract: This paper analyzes some theatrical pieces concerning the way they present elements of common and ordinary life. The proposal is that this staging of daily life implicitly suggests to the audience a more theatrical perception of their life. An immediate political consequence is the production of other possibilities of life, alternatives to hegemonic modes of feeling, and perspectives of art that can better feed theater classes in schools.

Keywords: Theatre reception, Theater education, Theater and politics.

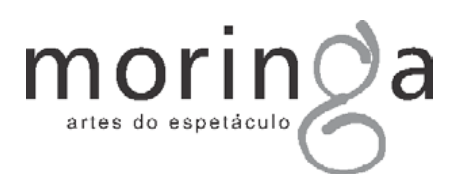


Um adolescente sentado em um sofá velho e vestindo short, camiseta e chinelo fala de sua vida de morador de favela e de como foi seu encontro com o teatro. A cena inicia a peça Cidade Correria, do Coletivo Bonobando (ALCURE, FLORÊNCIO, 2017, p. 90), e remete de maneira capciosa a clichês de trabalhos artísticos assistencialistas, ao mesclar relato autobiográfico redentor com piadas de fácil digestão. Violentamente, o ator é interrompido por uma horda de jovens que invade o palco com muito barulho e palavras de ordem rebeldes. Eles o tiram dali, numa ocupação irreverente que profana aquele espaço antes domesticado. De certo modo, a peça toda será como a entrada deles, com atuações realizadas com prazer sarcástico. O competente trabalho dramatúrgico e de preparação de atores aproveitou 0 que cada atuante tem de mais interessante e mais afeito a si. Sua vida é que será o material cênico, mas os temas não serão tão importantes quanto a forma como utilizam o palco: à vontade, apossando-se do teatro como de sua cidade, de sua vida.

\section{Identificação preliminar}

Nicolas Bourriaud (2009a) (2009b) (2011), ao examinar artistas contemporâneos que questionam lugares e concepções consolidados da arte, já acusa a indiferenciação entre, de um lado, uma suposta vida real e, de outro, a Arte como criação afastada da vida ordinária. Estes trabalhos são classificados por Bourriaud como "estética relacional": "uma arte que toma como horizonte teórico a esfera das interações sociais e seu contexto social, mais do que a afirmação de um espaço simbólico autônomo e privado" (BOURRIAUD, 2009a, p. 19). Esta definição pode ser considerada análoga ao que Jacques Rancière (2012, p. 56) denomina como "regime arquiético", e ao que Reinaldo Laddaga (2006, p. 21), anos antes, abordava como "estética de la emergência". Nos três casos, trata-se de trabalhos que tentam, de dentro dos fluxos cotidianos, desconstruir os códigos presentes na vida para uma reutilização, reocupação e reinvenção do mundo.

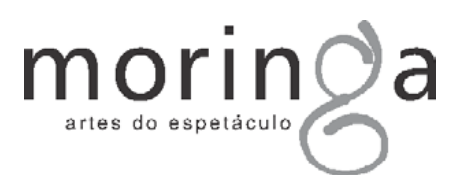


Um exemplo não citado por Bourriaud nestes livros (estranhamente, ele não menciona nenhum exemplo nomeadamente teatral), mas que contempla as mesmas questões, são os trabalhos do grupo Rimini Protokoll. Este grupo teatral alemão elabora propostas estéticas onde recortes da vida mais banal entram efetivamente em cena, não tanto na temática, mas principalmente pelo modo de empregar atores que são trabalhadores de telemarketing, caminhoneiros, operários de fábricas, pessoas "comuns", performando suas próprias funções profissionais. Como exemplo, nas peças 100\% City (sendo o "City" mudado para cada lugar em que a peça é performada), cem habitantes de uma cidade são escolhidos numa amostragem tipificada analogamente aos dados estatísticos populacionais (em termos de raça, gênero, etc.) e vêm ao palco para dar corpo aos números, numa crítica ao distanciamento que a mídia e o poder instituído promovem por seus dispositivos de controle.

\section{O comum e o cotidiano em palcos cariocas}

Obras artísticas que saiam do campo do grandioso $e$ extraordinário não são raras ou recentes. Mas, é importante atinar para como em um certo teatro contemporâneo, sendo mais enfocada aqui a cena carioca, a vida comum tem sido a protagonista de peças. Este "comum", aqui, seria sinônimo de ordinário, em oposição a extraordinário; aquilo que é banal, cotidiano, não especial, mas que, de certa forma, é "pertinente às pessoas de um modo geral, ou seja, ao coletivo, ao comunitário" (DA COSTA, 2014, p. 38).

Além de outros motivos e consequências que serão expostas mais adiante, friso, de início, a importância para alunos de teatro desta operação de estetização do cotidiano, uma vez que a abordagem cênica em sala de aula, que considere este tipo de teatralidade do comum e do ordinário, pode dialogar de maneira mais contundente com a vida dos alunos. Aspectos relativos à 
contextualização das aulas de teatro, por exemplo, podem melhor se encaminhar, porque operacionalmente na cena 0 suposto real (a vida do aluno) já se coloca como teatral. Como argumentarei adiante, a sensibilidade teatral para a vida cotidiana é aflorada e fomenta uma leitura e produção de mundo mais conectadas com elementos de teatralidade presentes na vida de todos.

Falaremos mais de Cidade Correria, mas este fenômeno começou antes, com peças que não só quebram estruturas ainda convencionais de dramaturgia, como constituem indefinições, borramentos entre os campos arbitrariamente definidos como ficcional e real. Podemos citar uma peça estreada em 2005 na cena carioca, $A$ falta que nos move ou todas as histórias são ficção, dirigida por Christiane Jatahy e transformada em filme no ano de 2012. Aproveitarei a maior facilidade de acesso ao filme e o tomarei como objeto de análise, levando em conta também sua grande similitude de roteiro com a peça teatral.
O filme $A$ falta que nos move (JATAHY, 2011) já se inicia com a exposição da equipe de gravação, durante os testes para a verificação dos equipamentos. Quando Kiko Mascarenhas, primeiro atorpersonagem a aparecer, chega à casa onde será ambientado o filme, ele cumprimenta o cameraman que o grava. E o que podemos dizer é que todo o início do filme é dedicado a isto: instituir a desestabilização das fronteiras entre o real e o ficcional, uma "derrota do real e da representação" (FÉRAL, 2009, p. 205). E esta desestabilização da recepção em quadros já consolidados de compreensão será aqui o mais evidente, como comenta, sobre esta obra, a própria diretora:

Essa é uma pergunta que eu ainda me faço, ou seja, como é que eu consigo uma atuação que caiba dentro do espaço cênico, mas se dê de uma forma tal que o espectador realmente fica em dúvida se aquilo que está vendo é uma atuação preparada ou se é uma experiência do momento presente. (JATAHY \& DA COSTA, 2015, p. 215)

Isto tudo ocorre sem transição ou advertências ao

Moringa Artes do Espetáculo, João Pessoa, UFPB, v. 10 n. 2, jun-dez/2019, p. 173 a 194

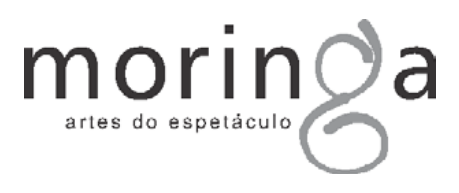


espectador. Assim sua percepção acaba por sair de seus lugares estabilizados, de seus regimes e ordens conhecidos, e se desloca para um "umbral" - analogamente ao que propõe Erika Fischer-Lichte, ao refletir sobre alguns efeitos da irrupção do real na cena teatral:

Quando, durante um
espetáculo, a percepção
muda repetidamente e, devido
a este fato, o espectador é
frequentemente transportado
a um estado entre as duas
ordens, tal diferença perde
cada vez mais sua pertinência
e, ao contrário, a atenção do
sujeito que percebe fixa-se na
ruptura da estabilidade, no
estado de instabilidade, na
passagem. (FISCHER-
LICHTE, 2013, p. 21)

Estas operações se intensificam, quando, por exemplo, Pedro Brício alega não saber que uma informação poderia ser falada "no filme", e quando Kiko solicita a outra atriz "dar uma olhada no roteiro" e a câmera, na sequência imediata, registra todos os atores checando quais dos eventos já ocorreram ou não dentro do esperado ("isso já foi...", "com o roteiro, ninguém tá nem aí!”). Ou quando Marina Vianna solta a pérola "ai, meu deus do céu, quando eu imagino meu pai vendo isso...", ao se enxugar após uma micção registrada no filme. $O$ espectador acaba, então, compelido a construir outros modos de discernimento sobre o que ocorre à frente à câmera.

Mas a câmera somos nós, não? Ao dirigir-se a quem registraobserva, 0 atuante remove 0 caráter especial de sua experiência, compondo uma equivalência entre aquilo que ele vive $e$ que vivemos ordinariamente, minando a relevância de julgarmos se aquilo deve ocorrer diante das câmeras ou fora do alcance delas. Nos filmes e peças mais comuns, com câmeras supostamente secretas e a instituição da quarta parede, o que vemos se situa num regime de simulada proteção do registro ou da presença alheia, como se o que ocorre na cena fosse autêntico justamente por não estar sob o olhar do espectador. Paradoxalmente, este natural na cena se distingue do que é comumente vivido pelo espectador,

Moringa Artes do Espetáculo, João Pessoa, UFPB, v. 10 n. 2, jun-dez/2019, p. 173 a 194

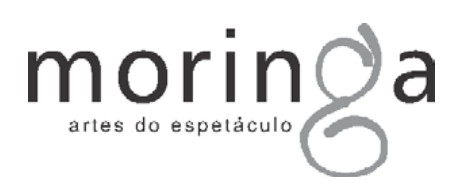


pelo fato de ser constituído como ficcional: sua artificialidade e distância da vida se comprova justamente pela forjada naturalidade diante da câmera, como se esta não existisse, como se o que ali ocorresse fosse real.

Ao se denunciar a presença da câmera e mesmo assim se continuar atuando (naturalmente?), há uma afirmação implícita de que a distinção não importa: se eu vivo - comum diante das câmeras (lugar reservado ao excepcional), o que se vive fora das câmeras poderia estar diante destas indiscriminadamente. O registrado e o livre de registro, o cênico e o cotidiano, se equivalem. $\mathrm{E} O$ mesmo ocorrerá, por inferência, entre o ficcional e o real.

A proteção para a ficção parece servir de fato para que o suposto real seja protegido. O espectador que vê algo protegidamente ficcional mantém o seu real protegido. Se o ficcional se desestabiliza, seu real também. 0 ficcional não é tão ficcional e o real não é tão real. Como implica o subtítulo da peça, nossas histórias de vida são ficção.
No caso de Cidade Correria, toda a peça é um trazer para a cena o cotidiano dos atores. Alguns figurinos são ostensivamente vulgares, como um pijama, um conjunto de saia jeans e camiseta, o kit short-camiseta-chinelo, já aqui mencionado, do ator da primeira cena. As cenas trazem o funk (que os atores recusam como referência, negando-se inutilmente a aderir a seu ritmo) e os personagens sociais que the são próximos: o pesquisador militante de políticas públicas, a apresentadora de programa de televisão, a filantropa demagoga neoliberal, o policial militar. $\mathrm{E} O$ momento de maior interatividade com a plateia é um jogo conhecido, ruas e vielas, que se mostra como um exorcismo destes demônios que assolam sua vida. Em uma cena bastante intensa, após esse jogo, um ator é obrigado por um PM a realizar um strip-tease em que as roupas tiradas em camadas são uniformes de trabalho que marcam papeis diversos, mas todos no mesmo nível socioeconômico: macacão de operário, uniforme de gari, de criada, de porteiro de prédio. O PM,

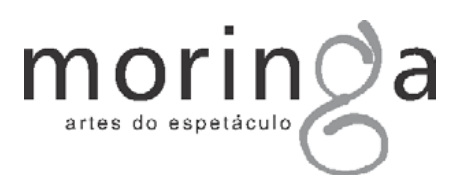


ao invés de matá-lo ou agredi-lo, como seria esperado no contexto, beija-o na boca, numa pacificação violadora. A referência ao cotidiano da maior parte da população brasileira não poderia ser mais exata.

\section{A vida reapropriada}

Se estas propostas cênicas dialogam desta maneira, de certo modo direta, com o comum, talvez seja porque implicitamente reconhecem ou propõem que 0 comum tenha estruturas estéticas. Michel de Certeau (1998) elaborou a ideia de que ações e modos de viver do cotidiano não estariam fadados à passividade inerte e inócua de puro consumo de uma produção previamente realizada. Aquele que Certeau chama de "homem ordinário. Herói comum, Personagem disseminada. Caminhante inumerável" (CERTEAU, 1998, p. 57) realiza uma atividade onde os campos de produção e consumo são indiscerníveis, e que apresenta outras "maneiras de empregar os produtos impostos por uma ordem econômica dominante" (CERTEAU, 1998, p. 39). Esta criação, uma poética não espetacular, consiste em uma "reapropriação", "reemprego" (CERTEAU, 1998, p. 52), uso cotidiano que opera uma resistência aos modos e maneiras de viver induzidos pelos produtos e estruturas definidos pelo sistema de produção e de capital, atualmente configurados como "política da dívida" (LAZZARATO, 2017). Estes enredos e roteiros estruturados que compõem nossa vida cotidiana são também denunciados por Bourriaud, principalmente quanto ao aspecto político:

A sociedade humana é estruturada por narrativas, por enredos imateriais que se traduzem em maneiras de viver, em relações no trabalho ou no lazer, em instituições ou em ideologias. Os responsáveis pelas decisões econômicas projetam cenários sobre 0 mercado mundial. $O$ poder político elabora previsões e planejamentos. Vivemos dentro dessas narrativas. Assim, o emprego segue o enredo dado pela divisão do trabalho;

casal 
heterossexual segue o enredo sexual dominante; a televisão e 0 turismo oferecem 0 enredo privilegiado para o lazer. (BOURRIAUD, 2009b, p. 49)

Para Bourriaud, os trabalhos artísticos relacionais e de pósprodução visam justamente atuar neste âmbito estético da vida definida convencionalmente como real, nestas estruturas sintéticas e previamente introduzidas nos aspectos cotidianos que vivemos de maneira clara ou não, percebida ou não. Estes artistas desnaturalizam estes quadros predefinidos e as fronteiras ilusórias entre "ficção" e "informação", utilizando e (re)(de)codificando estas formas. Produzem linhas narrativas divergentes, relatos e enredos alternativos, visando criar mundos outros que não os dominantes, mundos que concreta e poeticamente vivemos no dia a dia, aspectos e questões da vida coletiva e cotidiana.

Noto, oportunamente, que no livro "Jogos Teatrais", de Ingrid Dormien Koudela (2009, p. 37), é mencionado um dos elementos teatrais fundamentais no desenvolvimento da pessoa, a "imaginação dramática": percepção complexa dos eventos que nos cercam e constituem. A decodificação que estas formas artísticas colocam em evidência se dirige não só a formas estéticas mais abstratas, mas também a padrões narrativos, enredos da vida. E a prática pedagógica do teatro fomenta uma relação mais sofisticada com os borramentos entre real e imaginário, onde estes enredos são desnaturalizados e podem, assim, ser melhor reinventados.

A cena ordinária mimetiza ou metonimiza as potências da vida comum real, percebidas por Certeau (e muito antes, no século $\mathrm{XX}$, por criadores como Kafka, Musil, Beckett, etc.). Com isso, a cena do comum dialoga de maneira reversível e em realimentação com o comum da vida, enriquecendo-o e dinamizando mais ainda suas metamorfoses e invenções. E esta conexão diz respeito ao que Alain Kerlan, filósofo da educação estética, amparado nas ideias de John Dewey sobre a experiência, considera como importante

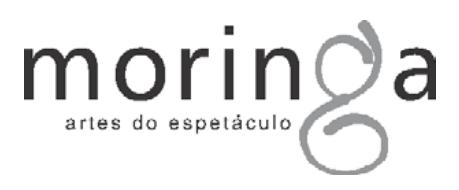


conquista democrática: "restaurar a continuidade entre a experiência estética e os processos normais da existência" (KERLAN, 2015, p. 276). O que conta então é a percepção e fomento de uma "politização das práticas cotidianas" (CERTEAU, 1998, p. 45), que constituem

táticas, "engenhosidades do fraco para tirar partido do forte". Mas este tipo de politização ou de caráter político posto em relevo aqui é fundamentalmente diferente do que se considerava político nos anos sessenta e setenta do século $X X$, quando, segundo Marina Vianna, no filme $A$ falta que nos move... (JATAHY, 2012) , "a vida tinha um porquê", e outros aspectos populavam e definiam a política:

o fortalecimento da função que o discurso individual do sujeito consciente (líder) exercerá como direcionador dos processos de libertação coletiva; a concepção unívoca do poder do qual se pretende libertar as massas oprimidas vistas apenas como sujeitadas e não como centros de transmissão do poder; a ideia de que os aspectos macropolíticos (gerais, ligados à organização do trabalho e da produção) é que constituem os fatores decisivos nos processos revolucionários, em detrimento das singularidades moleculares (micropolíticas), isto é, das subjetividades e, dos modos de subjetivação (estilos de vida, maneiras de experimentar o desejo e a sexualidade, sensos de pertencimento coletivo por critérios culturais, geracionais, étnicos, de gênero, etc.). (DA COSTA, 2010, p. 124)

Em outras palavras, o que é política e o que é trabalho cênico situam-se numa zona indefinida e inconclusa nestes trabalhos teatrais desespetacularizados e numa certa visão contemporânea de política, que percebe cada vez mais a partilha de modos de vida, modos de sentir e afetos como a real política (SAFATLE, 2016) - fato que constatamos nos confrontos das eleições brasileiras de 2018, claramente constituídos por rivalidades de modos de vida. Sintomaticamente, aos trinta e cinco minutos do filme $A$ falta que nos move..., numa discussão sobre indenizações a vítimas diretas da ditadura militar brasileira e sobre

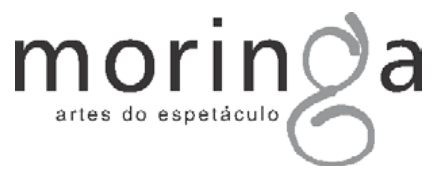


política, a frase “(...) quando política é, na verdade", proferida por Daniela Fortes, não é concluída. Talvez o filme afirme com isso não ter afirmações sobre o que seja política "na verdade".

\section{Linguagem repaginada}

Esta reocupação da vida e da arte pode ocorrer na recaptura de linguagens que se consolidaram e que convencionalmente servem a modos de fruição massificados ou pretensamente apolíticos, como na Pop Art. Podemos constatar esta operação na recente afluência ao teatro burlesco praticada por jovens performers no Rio de Janeiro. A plateia destes espetáculos, particularmente o Cabaré Diferentão, fomentado majoritariamente por Delirious Fênix (Isabel Chavarri), é formada, em sua maioria, por jovens que estão ali por declarado prazer voyeurístico ao fruir desta linguagem que mistura, com elementos tradicionais do cabaré, teatro, humor, dança e exposição sensual de corpos seminus. Linguagem associada ao machismo, este "burlesco repaginado" (nas palavras de Chavarri, presentes no documentário Yes, nós temos Burlesco) deleita também jovens mulheres que vêm assistir outras mulheres, e tem no palco homens que fazem o que antes não lhes era destinado - a exploração sexual leve e jocosa de seus corpos para um público menos sectário.

Os corpos femininos deste burlesco carioca saem do padrão de beleza que é ostentado pela mídia de massa e vinculado à permissão para se expor sensualmente o corpo (um padrão de formas excepcionais, não comuns). Os performers realizam seus números com sua aptidão ("o material que você tem", como especifica Isabel Chavarri) e com seus corpos como são, sem exclusões e adequações ocultadoras. Cito o depoimento de Miss G.: "Eu queria fazer dança. Sempre fui gordinha. Aí quando eu fiquei adolescente, eu vi que não era bem o meu lugar e fui pro teatro. Mas mesmo assim desse lugar eu fui me encontrando e fui cair no burlesco, que não é exatamente dança, mas não é

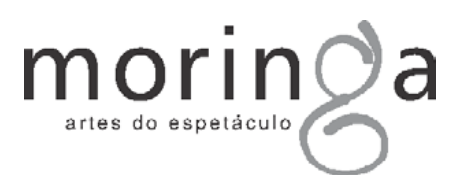


exatamente teatro" (CAFURE, 2015).

Estes performers ocupam o palco e ocupam o burlesco, ao entendê-lo e usá-lo "num outro lugar que não só o que geralmente se vê", como nota Chavarri. E suas identidades são expostas, de maneira fragmentada, mas intensa, pelo claro prazer que demonstram em performar suas cenas, que são compostas por seus desejos e suas visões estéticas de mundo e de si. Como em Cidade Correria, a aceitação de si é ostentada sem pruridos.

\section{O valor do que se vê e vive}

Mas é preciso notar complexidades e diversidade na presença deste comum na cena. Um exemplo de exposição pessoal que funciona de maneira ligeiramente diversa, mesmo que similar ao que aqui foi comentado, ocorre na peça BR-Trans, com Silvero Pereira. Neste trabalho, o relato (auto?)biográfico numa profusão de personagens vira indistinção de pessoas reais, agindo como facilitador de aproximação e aceitação a toda travesti": "o que interessa aqui é reiterar que a dramaturgia trata da massa das mulheres trans, não das exceções" (BARCELOS, 2015). A presença marcante, especial, de Silvero promove afeição do espectador com traços corporais e comportamentais que são normalmente rechaçados. Mesmo que cercado de polêmica (MONART, 2018), menor do que no caso do ator Luís Lobianco, em 2018, com a peça Gisberta, seu trabalho fomenta no espectador uma intimidade com pessoas tidas como exóticas, desespetacularizando este recorte do cotidiano e suas integrantes.

Prosseguindo na observação destes paradoxos, em alguns momentos da atuação de Enrique Diaz ao final da peça Otro, do Coletivo Improviso, há composições de forte lirismo e beleza poética, no sentido mais consagrado, imbricados com a aparência de ordinário na cena. No último momento em que aparece na peça, Enrique Diaz entra no

Sigo aqui a nomenclatura senso comum, marcando o poder da peça de atingir espectadores de modo abrangente. 
espaço do palco que fica mais em evidência, após o final da fala-cena de outro ator, Thierry Tremouroux (aqui, como em $A$ falta que nos move, todos se chamam pelo nome real). A fala de Thierry acaba de modo tocante, com vários "obrigado" que ele faz a uma pessoa a quem se refere em sua narração pessoal, mas dirigindo a fala à plateia, que se torna interlocutora e personagem desta narração (receptora, assim, dos agradecimentos tão francamente proferidos).

Diaz começa sua fala definindo "era só um dia comum", o que não é nada fortuito de sua parte, e prossegue "não é um dia ruim, é só um dia comum", como se tivesse de aliviar o termo "comum" da pecha de ser ruim ou irrelevante. Vai descrevendo suas ações, encontros, lugares, fatos ao longo de um dia em que renova sua carteira de motorista. Sua fala tem ritmo, volume e entonação calmos, estáveis, íntimos, num regime ou "orientação" de atuação similar ao definido por José da Costa ao comentar a peça Bodas de Sangue, dirigida por Amir Haddad: "essa orientação quanto ao trabalho atorial é a de valorizar a aparição da pessoa e da subjetividade do ator em cena, evitando ao máximo do possível que 0 intérprete/ atuador seja encoberto por traços de caracterização da personagem (...)" (DA COSTA, 2009, p. 14).

Seu texto é acompanhado pela projeção de fotos tiradas com seu celular naquele dia. Inicialmente, Diaz as muda com um notebook, mas após um tempo a mudança de imagens se torna automática, previamente preparada, transformando-se sutilmente em um vídeo a se desenrolar sem que tenhamos percebido seu início. Trata-se de imagens e música que vão se transformando de maneira orgânica com a fala de Diaz, conferindo a tudo um teor poético, lírico. A cena acaba por ser, sem que percebamos como, intensamente tocante.

Quando Diaz traz este dia "comum" e o estetiza de maneira sutil, quase imperceptível, como um mágico escondendo seu truque, ele sobrevaloriza esteticamente o cotidiano. Ele embute no que nos é habitual uma beleza talvez não

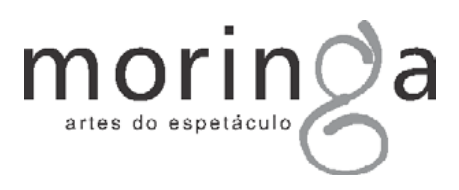


vista por alguns, e exerce um serviço de valorização da vida comum para aqueles que não a percebem como bela ou importante. Como já sugerido nos comentários sobre $A$ falta que nos move, o cotidiano e o ordinário são poetizados por um jogo de vai-evem, uma reversibilidade entre a vida supostamente real do espectador e a suposta ficção da cena.

\section{Performance e vida}

$\mathrm{Na}$ arte, o século $\mathrm{XX}$, principalmente em sua porção mais final, esteve repleto de práticas e pensamentos expressos de artistas que tocavam, de maneiras diversas e com grande variação de intensidades, estas relações artevida. Mas, como notou Gillian Sneed, estas obras, inclusive as nomeadas como relacionais, se devem a precedentes de realizações dos anos 1960, tendo como ponto nevrálgico trabalhos de Allan Kaprow:

[...] o artístico "desfoque da arte e vida" não é um fenômeno novo. Tendo suas origens nos rituais de antigas práticas teatrais e suas raízes modernistas nas vanguardas históricas, o seu recurso mais célebre e bem articulado chega a partir de meados do século $X X$ através dos escritos teóricos de Allan Kaprow. (SNEED, 2011, p. 170)

Protagonista do ápice das realizações de happenings e performances, Allan Kaprow, em seu ensaio The Education of the Un-Artist, escrito em 1971, tece um quadro de tensões e transformações ocorridas na Arte no século $\mathrm{XX}$, mais precisamente nos anos 1960, e detecta um tipo de arte, entre outros, que ele denomina e critica como "Arte arte", uma arte alijada do cotidiano ou do comum:

A Arte arte toma a arte de maneira séria. Ela presume, mesmo disfarçadamente, uma certa raridade espiritual, uma função superior. Ela tem uma fé, e isso é reconhecível pelos seus iniciados. Ela é inovadora, claro, mas muito mais em termos de uma tradição de ações e referências profissionalistas: a arte gera arte. Acima de tudo, 
a Arte arte mantém, para seu uso exclusivo, certos formatos e configurações sagrados, herdados de sua tradição: exibições, livros, gravações, concertos, arenas, templos, monumentos cívicos, palcos, exibições fílmicas e colunas de "cultura" da mídia de massa. Isto tudo confere credibilidade como as universidades conferem títulos $^{2}$. (KAPROW, 1971 [1993], p. 101)

Se tomarmos em conta diversas considerações $e$ atividades de artistas no século $\mathrm{XX}$, estando Kaprow incluído neste grande grupo, torna-se inevitável a percepção de uma visão mais expandida de arte e das suas propostas de vida e de educação. Esta percepção se dá tanto pela adoção dos conceitos e orientações declarados em escritos teóricos e manifestos, como pela escuta mais apurada de atividades artísticas da contemporaneidade. Para ilustrar estas questões com um exemplo cênico contemporâneo, com características que contemplam as questões levantadas acima, faço lembrar os trabalhos do grupo

\footnotetext{
${ }^{2}$ A tradução é minha.
}

Rimini Protokoll, já aqui mencionado.

Allan Kaprow, ao falar de educação e vida na segunda parte de sua obra Education of the UnArtist, partes I (1993) e II (2004), dedicará muitas páginas a falar sobre como o modo de operar advindo do trabalho governa quase todos os âmbitos da vida. Ele revela possuir um olhar acurado sobre a sociedade e por muitas vezes é bastante preciso sobre transformações que ocorreriam apenas décadas após este seu escrito. Não gratuitamente, elementos do sistema de trabalho estão presentes em obras artísticas nos anos 1960, como em 18 happenings in 6 parts, proposto pelo mesmo Kaprow, onde tarefas são executadas de maneira estritamente rigorosa. E, de fato, estas tarefas é que efetivamente compõem a estrutura mais expressa da obra: "o performer no happening meramente executa uma tarefa" (KIRBY, 1965 [1995], p. 6). Este "meramente", de início um recurso de fomento a abdicar de uma dramaticidade ou intencionalidade impostada, dá lugar a assumir o ato de performar

Moringa Artes do Espetáculo, João Pessoa, UFPB, v. 10 n. 2, jun-dez/2019, p. 173 a 194

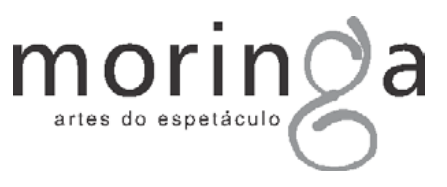


a atividade, a experiência de fazer como o grande objetivo estético. Este foco se consolida nas Atividades, propostas por Kaprow obras dirigidas aos praticantes, sem plateia, "cujo fim está em sua realização” (NARDIM, 2011, p. 107):
(leito de rio seco)
molhando uma pedra
carregando-a rio abaixo até que esteja seca
largando-a
escolhendo, lá, outra pedra
molhando-a
carregando rio acima até secar
largando-a. (NARDIM, 2011, p. 106)

A busca por uma efetividade no ato estético se dá nestes casos não quanto a seus resultados externos, mas principalmente nas pesquisas por aquilo que efetivamente constituiria a experiência estética daquele que performa, daquele que faz (no caso da educação, os alunos). Este tipo de direcionamento de foco no praticante da atividade, e não em um resultado para ser visto, pode ser identificado em diversas práticas cênicas, sendo um caso importante a Arte como veículo (GROTOWSKI, 2012, 129). Outro exemplo seria a operação pedagógica das Lehrstück de Brecht, onde "a separação entre atuantes e espectadores seria superada" (TEIXEIRA, 2014, p. 48). $E$ esta busca é um dos elementos principais no processo de transformações de atividades artísticas, digamos, baseadas na obra para uma arte baseada no evento (na ação, na performance). $\mathrm{Na}$ action painting e em ações de pintura do grupo Gutai, por exemplo, está em jogo uma questão fundamental que parece ser o cerne das motivações da performance: o que é pintura? seria o resultado ou o ato de pintar?

De certo modo, a atitude e as ações destas iniciativas são de resposta: é a performance, o ato artístico, o gesto aquilo que conta, aquilo que importa (em termos ordinários, cozinhar, e não comprar a comida pronta). Por conta disto, essas pesquisas e investigações desembocaram em trabalhos onde a construção de uma instância estética se dá de maneira bastante concreta (sendo a exploração da

Moringa Artes do Espetáculo, João Pessoa, UFPB, v. 10 n. 2, jun-dez/2019, p. 173 a 194

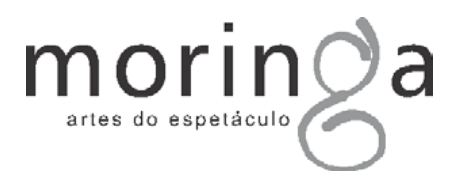


materialidade do corpo uma quase constante) e ao mesmo tempo mais delicada possível. Podemos notar, na performance, por exemplo, a constituição de uma temporalidade bastante específica, e a busca pelo gesto estético e por códigos específicos e singulares para cada trabalho, uma vez que a experiência estética fora dos apoios consagrados é que é ali o real valor. Como na busca do amor para além do casamento, fenômeno típico do século $X X$ que desemboca na chamada "relação pura”, observada pelo sociólogo Anthony Giddens (2002, p. 13), os formatos e locais já dominados pela arte são desprezados, numa busca de uma arte efetiva: o que se quer é o acontecimento, sendo a ação, a performance, vista como um suporte.

Assim, há neste processo histórico e nestas intenções uma operação importante para a educação teatral. Aqui, mais do que a arte se tornar vida, é a vida que se pretende tornar arte. A vida seria uma performance, a arte de fato. A operação perpetrada pela performance, bastante potente nos anos 60 e 70, ou as intenções implicadas ou que causaram estas operações, está estreitamente ligada com a extensão do âmbito artístico para a vida. As questões éticas destas transformações que levaram ao surgimento da performance estão também na perspectiva de desejo de uma vida estética.

Podemos avaliar as performances de Tehching Hsieh como um exemplo paroxístico destas fusões entre o cotidiano, o comum, o ordinário, a chamada vida pessoal e o sistema da arte. Este performer conseguiu construir performances de tamanha magnitude (particularmente as cinco One year performances) que tornaram sua vida indiscernível de seu trabalho artístico. Suas performances são sua vida e, no final, sintomaticamente, viver é sua última performance. $\mathrm{O}$ ponto nevrálgico desta questão é que Hsieh pode ter conseguido realizar trabalhos de valor artístico tão extremo justamente pelo extremo de mescla com sua vida que estas performances tinham.

Ao pensarmos a educação teatral, o movimento realizado pelo desejo artístico da performance

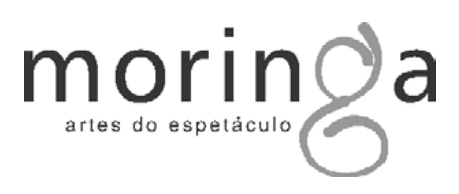


indica uma tomada de posição que deve ser enfatizada. A saída da valorização da obra para o ato de fazer, para o gesto, para a ação (a performance, enfim), constitui uma ética do acontecimento e do ato de fazer arte. Daquilo que ocorre ao fazermos arte, e não daquilo atinente ao seu resultado, como convencionalmente valorado - a obra feita. Se deslocamos isto para a educação, o que se configura é um direcionamento de nossos esforços para aquilo que acontece no aluno em termos teatrais, quanto e como o teatral opera nele dentro das aulas e após elas.

A importância destas reflexões jaz na possibilidade de reocuparmos estes substratos percepcionais - os enredos da vida, uma percepção mais teatral imbricada com o cotidiano - e utilizarmos suas riquezas para nós, reduzindo, na medida do possível, os problemas que sabemos existir neste âmbito e que, se não cuidamos deles, podem tanto empobrecer e mortificar nossa relação com o mundo.

\section{Vida e morte}

A importância de não apenas falar da vida, mas produzir novas formas de vida fica patente em Cidade Correria. Após o jogo Ruas e Vielas, e a cena do striptease dos uniformes profissionais, já mencionadas aqui, segue-se uma cena pungente em que uma jovem atriz de pijama traz ao palco, através das brincadeiras de faz de conta de uma criança ao ir sozinha para a cama dormir, a violência endêmica que assola gerações e da qual tentamos nos afastar e negar a existência. O público é confrontado com a violência doméstica, o incesto, o estupro de crianças, um assassinato. Após reclamar, de maneira ao mesmo tempo melodramática e sarcástica, da morte de seu filho (um boneco) pelo caveirão (um carrinho de brinquedo), ela boceja, o que opera um câmbio de regimes de sentido entre a violência recém abordada e a brincadeira ao dormir. A isto, se adiciona a atuação não realista que já complexifica mais ainda a referência ao real. Ao se deitar, ela se cobre, incluindo sua cabeça, 
numa alusão aos corpos produzidos por estes processos sociais que a cena denuncia.

Outro ator entra em cena e rabisca com giz, como um policial que marca um cadáver no chão, um quadrado ao redor da atriz deitada. Seu discurso sobre a cidade - o personagem principal que é composto por todos os atores-habitantes - tornará este quadrado 0 esquadrinhamento quase absoluto da urbe (sua estrutura urbana, suas regras, leis, ordens, controle e, talvez mais condicionante, a falta destes) que nos contém a todos como mortos, impotentes. Ele fala se equilibrando no limiar do quadrado, como numa corda bamba, e, ao neste entrar, dança e fala de si e da vida com poesia, sobrevivendo à cidade com este recurso.

O lirismo e a beleza se intensificam no que se segue: a longa fala de outra atriz, que se anuncia com uma voz sinceramente rouca: "eu sou a Cidade Correria!". Suas palavras são emitidas sem o verniz da formação convencional de ator. Nem da música bem escolhida e da beleza visual composta pelos outros atores soltando pipas e gritando com suavidade falas que aludem a jogos juvenis. Esta profusão cênica vai cedendo lugar ao ator com sua dança de resistência poética, num fade out de iluminação que insere, de vez, em nós, a plateia, a cidade destes atores, ocupando-nos com seus corpos, sua energia jovial e ao mesmo tempo madura, e novas propostas de vida.

\section{Velhas e novas formas de fazer política}

Em outubro de 2016, a jovem Ana Júlia discursa na Assembleia Legislativa do Paraná. Seu tema é a defesa da ocupação das escolas por estudantes secundaristas, e ela traz isto com seu corpo, sua presença frágil e perseverante, ocupando aquela assembleia com sua sincera e cuidadosa exposição. O vídeo está disponível para todos na internet, mas a jornalista Eliane Brum (2016) nos faz notar melhor o quanto seus espectadores ali presentes, os deputados escolados na velha política de aparências forjadas, não sabiam "que face botar na cara",

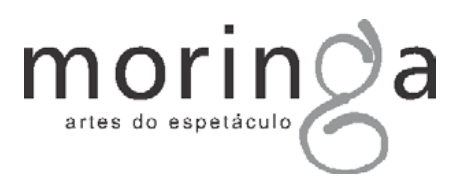


expondo uma desestabilização de moldes de recepção e de fazer empedernidos.

Os atores de Cidade Correria são, ainda, todos adolescentes, ou ao menos jovens. Seu questionamento cirurgicamente contundente da situação estabelecida é alimentado por sua expressão teatral responsável e despudorada. Eles não pedem licença para estar no palco, porque têm alegria por estar ali. Mostram que atuar pode ser se divertir - acertar é conseguir ser, num parcial absoluto onde se é grande por ser de seu tamanho, mesmo que ele seja comum. Sua existência no palco questiona e desnaturaliza 0 nosso cotidianamente vivido e abre brechas para que construamos outras percepções de nossas vidas, melhores "cotidianices", como menciona, mais recentemente, Eliane Brum (2018) ao abordar a degradação social e a corrosão do cotidiano acarretados pela adesão da população, nas eleições, a propostas reacionárias.

Nestes anos de incertezas, em que 0 ato político mais inequivocamente legítimo ainda é a ocupação das escolas por estudantes em sua grande parte usando short, camiseta e chinelo, esta ocupação do palco pelo ordinário pode ser uma resposta do teatro a questões de nossas vidas que talvez nem consigamos ainda elaborar.

Recebido em: 29/01/2019

Aceito em: 16/03/2019

\section{Referências Bibliográficas}

ALCURE, Adriana Schneider; FLORÊNCIO, Thiago. Procedimentos dramatúrgicos em Cidade Correria: ocupações urgentes, corpos insurgentes. In: $\mathbf{0}$ Percevejo Online. v. 9, n. 1, p. 89 a 104. jan-jun, 2017. Disponível em:

$<$ http://www.seer.unirio.br/index.ph p/opercevejoonline/article/view/688 5>. Acesso em: 24 nov. 2019.

BARCELOS, Mariana. O teatro político e a teatralidade. In: Questão de Crítica. Vol. VIII no 66, dezembro de 2015. Disponível em: <http://www.questaodecritica.com.b r/2015/12/br-trans/\#more-5595>. Acesso em: 24 nov. 2019.

Moringa Artes do Espetáculo, João Pessoa, UFPB, v. 10 n. 2, jun-dez/2019, p. 173 a 194

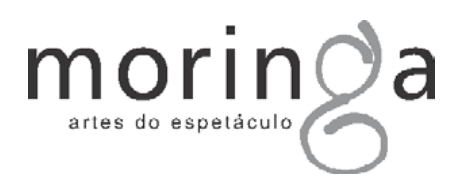


BOURRIAUD, Nicolas. Estética relacional. São Paulo: Martins Fontes, 2009a.

BOURRIAUD, Nicolas. Pósprodução: como a arte reprograma 0 mundo contemporâneo. São Paulo: Martins Fontes, 2009b.

BOURRIAUD, Nicolas. Formas de Vida - a arte moderna e a invenção de si. São Paulo: Martins Fontes, 2011.

BRUM, Eliane. Ana Júlia e a palavra encarnada. In: El País. Coluna da autora publicada em 31 de outubro de 2016. Disponível em: <http://brasil.elpais.com/brasil/2016 /10/31/opinion/1477922328_08016 8.html>. Acesso em: 24 de novembro de 2019.

BRUM, Eliane. Como resistir em tempos brutos. In: EI País. Coluna da autora publicada em 09 de outubro de 2018. Disponível em: $<$ https://brasil.elpais.com/brasil/201 8/10/08/opinion/1539019640_6539 31.html>. Acesso em: 24 nov. 2019.

CAFURE, Fabiano (Diretor). Yes, nós temos burlesco. Produção própria. 2015. Disponível em: <https://www.youtube.com/watch?v
$=A c E Y 6 c f x \mid z U>$. Acesso em: 24 nov. 2019.

CERTEAU, Michel de. A invenção do cotidiano - artes de fazer. Petrópolis: Editora Vozes, 1998.

DA COSTA, José. Irrupções do real no teatro Contemporâneo. In: SUBTEXTO - Revista de teatro do Galpão Cine Horto - Ano VI, dez 2009, no 6 . Belo Horizonte: Edições CPMT, 2009.

DA COSTA, José. Biopolítica e teatro contemporâneo. In: Revista LUGAR COMUM №30. Rio de Janeiro, 2010.

DA COSTA, José. Dentro e fora do teatro e da representação: modos de lidar com o comum e com o outro. In: Revista Sala Preta. V. 14, n. 2. 2014. Disponível em: <http://www.revistas.usp.br/salapret a/article/view/84740>. Acesso em: 24 nov. 2019.

FÉRAL, Josette . Por uma poética da performatividade: 0 teatro performativo. In: Revista Sala Preta - USP, 2009. Disponível em: $<$ http://www.revistas.usp.br/salapret a/article/view/57370>. Acesso em: 24 nov. 2019.

FISCHER-LICHTE, Erika. Realidade e ficção no teatro

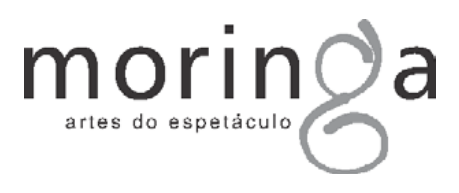


contemporâneo. In: Revista Sala Preta - vol. 13, n. 2. Tradução de Marcus Borja. São Paulo: USP PPGAC, 2013. http://dx.doi.org/10.11606/issn.2238 -3867.v13i2p14-32. Acesso em: 24 nov. 2019.

GIDDENS, Anthony. Modernidade e identidade. Rio de Janeiro: Zahar, 2002.

GROTOWSKI, Jerzy. Da companhia teatral à arte como veículo. In: RICHARDS, Thomas. Trabalhar com Grotowski sobre as ações físicas. São Paulo: Perspectiva, 2012.

JATAHY, Christiane (Diretora). A falta que nos move. Rio de Janeiro: Tambellini Filmes, 2012. Mais informações em: http://christianejatahy.com.br/projec t/a-falta-que-nos-move. Acesso em: 24 nov. 2019.

JATAHY, Christiane \& DA COSTA, José. Uma teia sobre o cotidiano entrevista concedida por Christiane Jatahy a José da Costa. In: Revista Sala Preta - vol. 15, n. 2. São Paulo: USP - PPGAC, 2015. http://dx.doi.org/10.11606/issn.2238 -3867.v15i2p211-230_.Acesso em: 24 nov. 2019.
KAPROW, Allan. The education of the un-artist. Part I. In: KAPROW, Allan. Essays on the bluring of art and life. Los Angeles: University of California Press, 1971; 1993.

KAPROW, Allan. A educação do anartista II. In: CONCINNITAS 6 Revista do instituto de artes da UERJ. Rio de Janeiro: UERJ, 2004. Disponível em: $<$ http://issuu.com/websicons4u/docs/r evista6>. Acesso em: 24 nov. 2019.

KERLAN, Alain. A Experiência Estética, uma Nova Conquista Democrática. In: Revista Brasileira dos Estudos da Presença. Porto Alegre, v. 5, n. 2, p. 266-286, maio/ago. 2015. Disponível em: $<$ http://www.seer.ufrgs.br/presenca>. Acesso em: 24 nov. 2019.

KIRBY, Michael. Happenings - an introduction (1965). In: SANDFORD, Mariellen R. Happenings and other acts. London and New York: Routledge, 1995.

KOUDELA, Ingrid Dormien. Jogos Teatrais. São Paulo: Perspectiva, 2009.

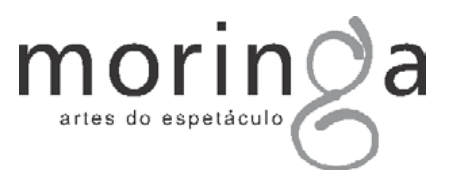


LADDAGA, Reinaldo. Estética de la emergencia. Buenos Aires: Adriana Hidalgo Editora, 2006.

LAZZARATO, Maurizio. A política da dívida é a "verdadeira" biopolítica. Entrevista para a Revista IHU Online. UNISINOS: 12 de outubro de 2017. Disponível em: <http://www.ihu.unisinos.br/159noticias/entrevistas/572574-apolitica-de-guerra-da-dividaentrevista-especial-com-mauriziolazzarato>. Acesso em: 24 nov. 2019.

MONART - Movimento Nacional de Artistas Trans. Carta Aberta. In: Revista Cult, fev. 18. São Paulo: Bregantini, 2018. Disponível em: <https://revistacult.uol.com.br/home /carta-aberta-do-movimentonacional-de-artistas-trans/>.

Acesso em: 24 nov. 2019.

NARDIM, Thaíse. As atividades de Allan Kaprow: artes de agir, obras de viver. In: Revista-Valise, v. 1, n. 1, julho de 2011. Disponível em: <https://seer.ufrgs.br/RevistaValise/ article/view/19892>. Acesso em: 24 nov. 2019.
SAFATLE, Vladimir. O Circuito dos Afetos. Corpos Políticos, Desamparo e o Fim do Indivíduo. Belo Horizonte: Autêntica, 2016.

SNEED, Gillian. Dos Happenings ao Diálogo: Legado de Allan Kaprow nas práticas artísticas "relacionais" contemporâneas. In:

Revista Poiésis, Revista do Programa de Pós-Graduação em Estudos Contemporâneos das Artes, n. 18, p. 169-187, dez. 2011. Disponível em: <http://www.poiesis.uff.br/PDF/poie sis18/Poiesis_18_TRAD_Happenin gs.pdf>. Acesso em: 24 nov. 2019.

TEIXEIRA, Fran. As peças didáticas de Brecht - tensões produtivas entre texto e cena. In: Revista Repertório, UFBA, Salvador, $n^{\circ}$ 23, p. 46-57, 2014. Disponível em $<$ https://portalseer.ufba.br/index.php/r evteatro/article/view/12755/9029>. Acesso em: 24 de nov. 2019.

\footnotetext{
RANCIÈRE, Jacques. O espectador emancipado. São Paulo: Martins Fontes, 2012.
}

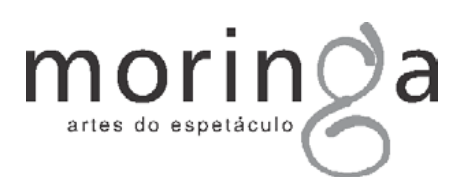

